\title{
Free Radicals, Oxidative Stress and Oxidative Damage in Parkinson's Disease
}

\author{
Marisa G. Repetto, Raúl O. Domínguez, \\ Enrique R. Marschoff and Jorge A. Serra \\ School of Pharmacy and Biochemistry, \\ University of Buenos Aires (UBA) / PRALIB - CONICET \\ Argentina
}

\section{Introduction}

Parkinson's disease (PD) is an adult-onset disease of unknown etiology, with a prevalence of $0.3 \%$ in the entire population, affecting more than $1 \%$ of humans over 60 years of age. Primary degeneration occurs in pigmented dopamine-containing neurons in the pars compacta of the substantia nigra, with projections to the striatum and typical motor signs that appear with a loss of $60 \%$ of the dopaminergic neurons of the brain area. While $90-95 \%$ of PD cases have no known genetic basis, approximately 5-10\% arises from inherited mutations (Farooqui \& Farooqui, 2011). While the actual physiopathology of PD remains uncertain, it is currently suggested that the molecular mechanism of the vulnerability of dopaminergic neurons in the substantia nigra involves monoamine oxidase-mediated abnormal dopamine metabolism, hydrogen peroxide generation, and abnormal mitochondrial and proteosomal dysfunctions along with microglia cell activation which may be closely associated with neurodegenerative process. The loss of dopaminergic neurons in the substantia nigra may be related to resting tremor, rigidity, bradykinesia, postural instability, and gait disturbance in PD patients. Also associated with PD neuropathology are disrupted iron homeostasis, intracellular deposition of proteins in Lewy bodies, and oxidative stress and neuronal damage.

$\mathrm{PD}$ is considered the paradigm of $\alpha$-synucleinopathies within the spectrum of neurodegenerative diseases that exhibit $\alpha$-synuclein in cytosolic protein aggregates (Navarro et al., 2009).

There is evidence that oxidative stress participates in the neurodegeneration (Lustig et al., 1993; Famulari et al., 1996; Repetto et al., 1999; Fiszman et al., 2003; Domínguez et al., 2008); neutrophils express a primary alteration of nitric oxide release in PD patients, where reactive oxygen species and oxidative stress parameters are more probably related to the evolution of PD (Gatto et al., 1996; Gatto et al., 1997; Repetto \& Llesuy, 2004). Peripheral markers of oxidative stress in red blood cells of neurological patients could be a reflection of the brain condition and suggests that oxygen free radicals are partially responsible for the damage observed in PD living patients (Serra et al., 2001; Repetto, 2008). Other reports suggest that mitochondrial dysfunction and impairment of the respiratory complexes are associated with the neuronal loss (Boveris \& Navarro, 2008). Moreover, increased mDNA deletions were recognized in nigral neurons in PD (Bender et al., 2006). 


\subsection{Clinical criteria diagnosis in idiopathic Parkinson's disease}

The differential diagnosis of parkinsonian syndromes is considered one of the most challenging in clinical neurology. Despite published consensus operational standards for the diagnosis of idiopathic Parkinson's disease (PD) and the various parkinsonian disorders, such as secondary Parkinson's disease, progressive supranuclear palsy, multiple system atrophy and corticobasal degeneration, the clinical separation of PD requires the application of strict diagnostic criteria.

The diagnosis of the specific secondary Parkinsonism was based on the constellation of clinical features suggestive of a secondary etiology (Gibb et al., 1988; Quinn, 1989; Dalakas et al., 2000; Schrag et al., 2002), namely: Manifestations and suspected etiologies of non PD, Vascular Parkinsonism, Drug-induced Parkinsonism, Multiple System Atrophy, Lewy body dementia, Toxin exposure (carbon-monoxide poisoning), Progressive supranuclear palsy, Hemiparkinsonism - hemiatrophy, Juvenile Parkinsonism with dystonia and hemiatrophy, Walking apraxia-ataxia frontal lobe, Action or postural tremor prominent (essential tremor) and the Stiff person syndrome.

While the clinical characteristics of the Parkinson syndrome facilitate the diagnosis, which is easy in the advanced stages in the paucisymptomatic forms or at the early stages the diagnosis becomes more difficult.

In the absence of a biological marker diagnosis in life can only be performed by clinical criteria. In recent decades the criteria used were not universally recognized, and the PD could be over diagnosed. In a study carried out between 1999 and 2000 (Serra et al., 2001) patients were recruited if they had, at least, two cardinal symptoms of PD according to clinical criteria (Hughes et al., 1992) and, additionally, Hoehn and Yahr stage 1 to 3 (Hoehn $\&$ Yahr, 1967), to assess the severity at presentation and progression. Patients also required a history of positive response to levodopa therapy.

Currently, the diagnosis of PD follows the United Kingdom Brain Bank Criteria, which demands bradykinesia and one additional symptom, i.e., rigidity, resting tremor or postural instability. The latter is not a useful sign for the early diagnosis of PD, because it does not appear before Hoehn and Yahr stage 3. Other symptoms of PD which precede the onset of motor disturbances are hyposmia, REM sleep behavioral disorder, constipation and depression. The clinical diagnosis of PD can be supported by levodopa or apomorphine tests. Imaging studies such as cranial CT or MRI are helpful to distinguish PD from atypical or secondary Parkinson's disease.

In the last decade the Unified Parkinson's Disease Rating Scale (UPDRS) is the most widely used clinical rating scale for PD. Authors unanimously considered the concept of a single clinical rating scale to be an important tool for clear and consistent communication among movement disorder colleagues (Fahn et al., 1987; Movement Disorder Society Task Force, 2003).

\subsection{Biochemical mechanisms associated to Parkinson's disease}

The degradation processes of macromolecules, such as serotonin, norepinephrine, dopamine, and other neurotransmitters of dopaminergic neurons in substantia nigra, catalyzed by monoamine oxidase are critically important not only for the regulation of emotional behavior, but also for other neural functions. As a consequence, the brains of PD patients are subject to high levels of oxidative stress. The dopaminergic cell loss and disease progression are accompanied by the accumulation of high iron levels, associated with aggregation of $\alpha$-synuclein (especially in the mutated form found in familial Parkinson's 
disease). Increasing evidence indicates that multiple biochemical and cellular factors are involved in neuronal death in PD, some of them involve protein dyshomeostasis, mitochondrial impaired function and metal-induced toxicity. These processes contribute to the oxidative stress and damage and inflammatory response in brain of PD patients (Farooqui \& Farooqui, 2011). The current views on PD consider that this disease is not only characterized by substantia nigra dysfunction but that it also involves the frontal cortex with a cognitive decline at the early stages of Parkinsonism (McNamara et al., 2007). Oxidative damage and mitochondrial dysfunction in the human frontal cortex are considered factors that lead to impaired cognition in PD patients.

\subsubsection{Protein dyshomeostasis}

The neuropathological hallmarks of PD include the presence of Lewy bodies mostly composed of $\alpha$-synuclein, a presynaptic protein that not only plays an important role in neuropathology of PD, but is also known to bind divalent metals as iron (Fe) and copper $(\mathrm{Cu})$, which accelerates the aggregation of $\alpha$-synuclein to form various toxic aggregates in vitro. Although the normal biological function of this protein remains to be elucidated, it is clear that regulation of its expression is essential for healthy neuronal function. Even a 1.5 fold elevation in its expression is sufficient to produce Lewy body disease (Sigletton et al., 2003). Membrane-bound $\alpha$-synuclein may play a role in fibril formation. Overexpression of $\alpha$-synuclein impairs mitochondrial function and increases oxidative stress. This prion protein has a neuroprotective function by acting as antiapoptotic factor that inhibits the mitochondria-mediated apoptosis by preventing the formation of the permeability pore of the inner mitochondrial membrane (Opazo et al., 2003; Kozlowski et al., 2009).

These effects are associated to mitochondrial dysfunction due to decreased activity of cytochrome c oxidase and to the increased production of reactive oxygen species, which in turn triggers mitochondria-mediated apoptotic neurodegeneration (Rossi et al., 2004; Spencer et al., 2009).

\subsubsection{Mitochondrial impaired function}

Neurochemically, PD is characterized by mitochondrial dysfunction and brain mitochondrial oxidative damage. There are also consistent observations of the impaired functioning of mitochondrial respiratory transport chain at the site of complex I (NADH CoQ10 reductase), from PD brain, particularly in the substantia nigra, with consequent aggregation and accumulation of $\alpha$-synuclein (Opazo et al., 2003; Friedlich et al., 2009) and in frontal cortex in PD patients (Boveris \& Navarro, 2008). The inhibition of complex I observed in PD has an etiological impact. The question then arises as to the origin of the complex I-deficiency in PD. It could result from an environmental toxin or an acquired or inherited mtDNA mutation(s) (Petrozzi et al., 2007).

The molecular mechanism involved in the inactivation of complex I is likely accounted by the sum of peroxinitrite mediated reactions, reactions with free radical intermediates of the lipid peroxidation process and amine-aldehyde adduction reactions. The inhibitory effects on complex I lead synergistically to denaturation of the protein structure and to further increases of superoxide anion $\left(\mathrm{O}_{2}^{-}\right)$y peroxinitrite production at the vicinity of complex I (Navarro et al., 2009; Navarro \& Boveris, 2009).

Inhibition of complex I creates an environment of oxidative stress that ultimately leads to the aggregation of $\alpha$-synuclein with the consequent neuronal death. Complex I dysfunction, 
also called "complex I syndrome" results in complex I inactivation, reduced oxygen $\left(\mathrm{O}_{2}\right)$ uptake and ATP formation, increased $\mathrm{O}_{2}$ - formation, oxidative stress and lipid peroxidation, events that lead to neuronal depolarization and contribute to excitotoxic neuronal injury (Opazo et al., 2003; Kozlowski et al., 2009; Navarro \& Boveris, 2009). Mitochondrial dysfunction in the human frontal cortex is to be considered a factor contributing to impaired cognition in PD in comparison to age-matched healthy controls. The mitochondrial impairment observed in frontal cortex in PD patients is properly described as a reduced frontal cortex respiration, with marked decrease in complex I activity, associated with oxidative damage, the latter determined by the increased content of phospholipids and protein oxidation products (Navarro et al., 2009).

Deficient complex I function would likely increase production of superoxide anion by impairing electron flow from $\mathrm{NADH}$ to ubiquinone, promoting oxidative stress through subsequent superoxide dismutase and Fenton chemistry. Similar deficits in respiratory transport chain complex I have also been reported in peripheral cells (myocytes and platelets).

Mitochondrial metabolic abnormalities, DNA mutations and oxidative stress contribute to ageing, the greatest risk factor for neurodegenerative diseases. Somatic mitochondrial DNA mutations have been reported in PD brain. These findings are important because the mitochondrial DNA encodes components of the respiratory transport chain complexes, and such mutations may impair efficient electron flow from $\mathrm{NADH}$ to molecular oxygen (Friedlich et al., 2009). Further, mitochondrial abnormalities occur early in most of the neurodegenerative disorders, and the evidence of specific interactions of disease-related proteins with mitochondria represents ultimate proof of mitochondrial involvement in neurodegeneration.

Mitochondria are targets of metal toxicity, and in many cases a close link between metalinduced oxidative stress, and damage and mitochondrial dysfunction has been established (Navarro \& Boveris, 2004, Navarro \& Boveris, 2009; Navarro et al., 2009, Navarro et al., 2010).

\subsubsection{Transition metals toxicity}

Increasing evidence indicates that metal-induced toxicity is associated with the etiology of neurodegenerative diseases. Two main mechanisms are currently considered likely to be the mechanism for redox active metals: a Haber-Weiss reaction and a depletion of major sulfhydryls, reduced glutathione and protein -SH groups (Repetto \& Boveris, 2011).

The cellular and tisular levels of transition metals are apparently determined by regulatory proteins and metallochaperons that control metal capture, transport and storage. The major consequences of metal dyshomeostasis are mitochondrial dysfunction, oxidative stress and mitochondrial genomic damage which enhanced activation of the apoptotic machinery (Kozlowski et al., 2009).

Transition metals including iron (Fe) mediated oxidative damage to cellular components through the one-electron transfer called the Fenton reaction $\left(\mathrm{Fe}^{2+}+\mathrm{H}_{2} \mathrm{O}_{2} \longrightarrow \mathrm{Fe}^{3+}+\mathrm{OH}+\right.$ $\left.\mathrm{OH}^{-}\right)$, which leads to production of the unstable hydroxyl radical $(\mathrm{OH}$.) that will oxidize nucleic acid, protein, carbohydrate and lipid, whichever is proximate (Halliwell \& Gutteridge, 1984). Disrupted iron metabolism is implicated in PD, iron levels are increased in the PD substantia nigra, associated with $\alpha$-synuclein pathology, substantial iron deposits are associated with neuronal loss, gliosis and Lewy body pathology. Iron sequestered in 
Lewy bodies and other pathobiologic pools of iron in PD brains has the potential to promote Fenton chemistry and oxidative damage to macromolecules. Evidence of oxidative damage to macromolecules is abundant in post-mortem PD tissue, with proteins, nucleic acids, lipids and sugars, all showing evidence of oxidative modification.

The mitochondria of Fe-treated rats show lower respiratory control in association with higher resting (state 4) respiration. This mitochondrial uncoupling elicited by Fe-treatment does not affect the phosphorylation efficiency or the ATP levels, indicating a mild degree of uncoupling in Fe overload (Pardo Andreau et al., 2009).

The Fe accumulation in substantia nigra (with up to $255 \%$ increases) results in oxidative stress; oxidative damage, decreased reduced glutathione levels and increased dopamine neuronal toxicity (Kozlowski et al., 2009). The Fe-induced oxidative damage to mitochondria contributes to the cellular death mechanisms, arising from a diminished respiratory chain activity and ATP production. The significant reduction in transferrin levels, observed in patients with Parkinson's diseases, is a factor contributing to increase Fe concentrations (Kozlowski et al., 2009; Spencer et al., 2011).

$\mathrm{Fe}$ and $\mathrm{Cu}$ are prevalent in human tissues, including the brain, and altered levels of these essential metals have been found in brain tissues of patients with neurodegenerative diseases (Repetto \& Boveris, 2011). Because approximately $20 \%$ of the total $\mathrm{Cu}$ is stored in the nucleus, DNA is the major target for copper-catalyzed oxidations. Accumulation of oxidative DNA base modifications, produced by dopamine and other catecholamine neurotransmitters and neurotoxins, is associated with elevated copper $(\mathrm{Cu})$ levels in the presence of $\mathrm{O}_{2}{ }^{-}$and $\mathrm{H}_{2} \mathrm{O}_{2}$ and potentially results from one-electron oxidation and/or the site-attack of hydroxyl radicals via a DNA-Cu(I)OOH complex. Because accumulation of oxidative DNA has been reported as a major contributing factor to genomic instability and mitochondrial dysfunction in aging and neurodegenerative disorders as Alzheimer and PD, it probably contributes to neuronal death associated with these degenerative processes (Spencer et al., 2011).

\subsubsection{Oxidative stress and oxidative damage}

The concept of oxidative stress is defined as an imbalance with increased oxidants or decreased antioxidants (Sies, 1991). As an imbalance situation, it implies that in the normal physiological condition there is a balance, or a controlled situation of quasi-equilibrium between oxidants and antioxidants. Oxidants are continually produced as secondary products of respiration and oxidative metabolism and antioxidants are continually reacting with oxidant molecules. In the oxidative stress condition, oxidants increase or antioxidants decrease in a progressive and continuous form, sometimes including adaptive responses that involve the synthesis of antioxidants and antioxidant enzymes and that confer elasticity and reversibility to the biological situation of oxidative stress (Boveris et al., 2008). They defined the intracellular oxidative stress as a situation where increases of the steady-state concentrations of any intermediate produces an increase in oxidant intermediates, an increase in the chain reaction rate and a decrease in intracellular antioxidants.

The brain is particularly susceptible to oxidative stress due to its high-energy demand and the specialized redox activities of neurons. Although the brain only constitutes 2 to $3 \%$ of total body mass, it utilizes $20 \%$ of basal oxygen supplied to the body. Low level of oxidants are needed for normal cellular functions, including, but not restricted to the regulation of neuronal excitability via redox-sensitive ion channels, synaptic plasticity, gene transcription, and the activity of enzymes controlling protein phosphorylation. At higher concentrations, 
oxidants cause neuronal membrane damage. The biological targets of oxidants include membrane proteins, unsaturated lipids and DNA.

Oxidative stress promotes aggregation and accumulation of $\alpha$-synuclein, characteristic of Parkinson's disease (Kozlowski et al., 2009; Opazo et al., 2003). The series of observed changes include glycation protein oxidation, lipid peroxidation, depletion of antioxidants and nucleic acid oxidation (Famulari et al., 1996; Gatto et al., 1996; Gatto et al., 1997; Repetto et al., 1999; Fiszman et al., 2003; Boveris et al., 2008; Repetto, 2008). It has been proposed that oxidative damage favors the aggregation of $\alpha$-synuclein in sporadic PD.

According to a now classical definition, antioxidants are molecules which, when present in small concentrations compared to the biomolecules that are supposed to protect, can prevent or reduce the extent of oxidative destruction of biomolecules. They can prevent initiation or intercept the lipid peroxyl radical involved in the propagation phase. In human plasma there are transition metal binding proteins in order to prevent metal catalysis; on the other side, cell membranes and lipoproteins contain lipophilic antioxidants, which are able to react with lipid peroxyl radicals, eventually terminating the chain reaction of lipid peroxidation. The implication of free radicals in various pathological processes has been detected in an increasing number of human diseases. The assay of oxidative stress parameters has brought substantial insights into the pathogenesis of many diseases in humans, by demonstrating the involvement of free radicals and/or the decrease of antioxidants.

\subsubsection{Lipid peroxidation}

Lipid peroxidation is a chain reaction initiated by the hydrogen substraction or addition of an oxygen radical, resulting in the oxidative damage of polyunsaturated fatty acids (PUFA). Since polyunsaturated fatty acids are more sensitive than saturated ones, it is obvious that the activated methylene ( $\mathrm{RH})$ bridge represents a critical target site. Molecular oxygen rapidly adds to the carbon-centered radical (R.) formed in this process, yielding to lipid peroxyl radical (ROO). The formation of peroxyl radicals leads to the production of organic hydroperoxides, which, in turn, can subtract hydrogen from another PUFA. This reaction is termed propagation, implying that one initiating hit can result in the conversion of numerous PUFA to lipid hydroperoxides. In sequence of their appearance, alkyl, peroxyl and alkoxyl radicals are involved. The resulting fatty acid radical is stabilized by rearrangement into a conjugated diene that retains the more stable products including hydroperoxides, alcohols, aldehydes and alkanes. Lipid hydroperoxide (ROOH) is the first, comparatively stable, product of the lipid peroxidation reaction. In conditions in which lipid peroxidation is continuously initiated it gives non-radical products (PNR), destroying two radicals at a time. In the presence of transition metal ions, $\mathrm{ROOH}$ can give rise to the generation of radicals capable of re-initiating lipid peroxidation by redox-cycling of these metal ions (Halliwell \& Gutteridge, 1984).

Lipid peroxidation can have significant downstream effects and possibly play a major role in cell signaling pathways. For example, the mitochondrion lipid cardiolipin makes up to $18 \%$ of the total phospholipids and $90 \%$ of the fatty acyl chains are unsaturated. Oxidation of cardiolipin may be one of the critical factors initiating apoptosis by liberating cytochrome c from the mitochondrial inner membrane and facilitating permeabilization of the outer membrane. The release of cytochrome c activates a proteolytic cascade that culminates in apoptotic cell death (Navarro \& Boveris, 2009). 
Many of these products can be found in biological fluids, as well as addition-derivatives of these very reactive end-products. As a result of lipid peroxidation a great variety of aldehydes can be produced, including hexanal, malondialdehyde (MDA) and 5hydroxynonenal (Repetto, 2008). Oxidation of an endogenous antioxidant reflects an oxidative stress that is evaluated by measuring the decrease in the total level of the antioxidant or the increase in the oxidative form. The only way not to be influenced by nutritional status is to measure the ratio between oxidized and reduced antioxidants present in blood. The published literature provides compelling evidence that MDA represents a side product of enzymatic PUFA-oxygenation and a secondary end product of non enzymatic (autoxidative) fatty peroxide formation and decomposition. Conceptually, these two facts indicate that MDA is an excellent index of lipid peroxidation. With biological materials, it appears prudent to consider the TBARS test more than an empirical indicator of the potential occurrence of peroxidative lipid damage and not as a measure of lipid peroxidation (Repetto, 2008).

\subsubsection{Inflammation}

Among neural cells, neurons are particularly vulnerable to oxidative damage, not only as a consequence of mitochondrial dysfunction (Boveris \& Navarro, 2008), but also due to inactivation of glutamine synthetase, which reduces the uptake of glutamate by glial cells and increases glutamate availability at the synapse producing excitotoxicity. Oxidative damage to lipids and protein of neuronal membrane affects activities of membrane-bound enzymes, ion channels and receptors. Glial cell's response to oxidative stress-mediated neurodegenerative process is extremely complex. Astrocytes may play a dual function, either protecting neurons from excitotoxicity through glutamate uptake system, or contributing to the extracellular glutamate via reversed glutamate transporter. They may contribute to the inflammatory response by transforming themselves into activated microglia and also release matrix metalloproteinase's, oxidants, prostaglandin $E_{2}$ and proinflammatory cytokines such as TNF- $\alpha$ and IL- $\beta 1$ (Farooqui \& Farooqui, 2011). In addition, at the site of neurodegenerative process, neural and non-neural cells express and secrete cytokines, chemokine and complement proteins, which also play important roles in induction, propagation and maintenance of inflammatory response. Cytokines are major effectors of the inflammatory response; they produce their effects by interacting with specific membrane associated receptors. Although physiological levels of cytokines are necessary for normal neuronal function and survival, the increased secretion of cytokines during neurodegenerative process may be detrimental to neurons.

Nitric oxide (NO) is a free radical and potent biological effectors regulating blood vessel dilatation and immune function and serve as a neuronal messenger in the nervous system. Most of the effects of NO are mediated by glutamate, although in high concentrations, may act as a neurotoxin. NO can react with superoxide anion to produce peroxinitrite, an even more potent oxidant associated with lipid peroxidation and cytotoxic effects, in part through the oxidizing of tissue sulfhydrils. Metabolic alterations in circulating blood cells are widely accepted as representative of similar central nervous system changes in human PD. Increased NO release of neutrophils and decreased catalase activity in erythrocytes were observed at the beginning of $\mathrm{PD} ; \mathrm{H}_{2} \mathrm{O}_{2}$ release by neutrophils and mitochondrial impaired function may be later signs in PD (Gatto et al., 1996). 


\subsection{Clinical evidence of oxidative stress and damage in Parkinson's disease}

Human neurodegenerative diseases are characterized by cumulative neuronal damage that leads to neurological deficits when neuronal loss reaches a critical level. Actually, the clinical evolution of patients with neurological diseases is based on psychological tests. The current hypotheses are that brain oxidative stress and damage are involved in the pathogenesis of neurodegenerative diseases such as Alzheimer's and Parkinson's diseases and nonneurodegenerative vascular dementia. Involvement of oxidative stress in the pathogenesis of PD is supported both, by postmortem studies and by studies showing the increased level of oxidative stress in the substantia nigra pars compacta (Boveris \& Navarro, 2008). Under normal conditions, the continuous generation of oxidants is compensated by the powerful action of protective enzymes: superoxide dismutase (SOD), catalase and glutathione peroxidase. Oxidative stress may be a consequence of reduced efficiency of these endogenous antioxidants that may render PD patients more susceptible to oxidative stress. Increases of pro-oxidants, as $\mathrm{H}_{2} \mathrm{O}_{2}$ and nitric oxide (NO), and decreases of antioxidants, either enzymatic or non enzymatic compounds, are considered an indication of oxidative stress. Oxidative damage is characterized by increases in the levels of the oxidation products of macromolecules, such as thiobarbituric acid reactive substances (TBARS), and protein carbonyls.

Oxidative stress, to which neurons are highly susceptible, is also known to induce oxidative changes in human red blood cells (RBCs), in vivo and in vitro (Gatto et al., 1996; Repetto \& Llesuy, 2004, Repetto, 2008). Based on the hypothesis that oxidative changes are not organ specific, their activities may be evaluated in peripheral and red blood cells.

The situation of oxidative stress evaluated by the peripheral markers of oxidative stress in the blood of neurological patients, seem to provide a reflection of the brain condition. Brain oxidative stress, with oxygen free radicals being responsible for brain damage, signals to peripheral blood, at least, through the diffusible products of lipid peroxidation. The peripheral markers provide a useful tool to determine the evolution of brain oxidative stress in neurological patients (Repetto, 2008).

\section{Materials and methods}

\subsection{Patients}

The clinic diagnostic of PD is realized in accordance with the "United Kingdom Parkinson Disease Brain Bank Criteria". Patients ( $n=15$, age $=66 \pm 4$ years) were evaluated according to the Hoehn and Yahr's scale in stages 1 to 3, and required a history of positive response to levodopa therapy. No patient presented vascular lesions on CT scanning. The controls groups (Table 1 and Table 2) consisted of 75 and 80 healthy people of $58 \pm 2$ years and $71 \pm$ 10 years, respectively.

\subsection{Peripheral markers of oxidative stress}

Blood was obtained by venipuncture and placed into glass tubes with heparinised syringes for separation of erythrocytes or mononuclear cells.

To determine tert-butyl hydroperoxide-initiated chemiluminescence (BOOH-CL), heparinised blood samples were centrifuged at $300 \mathrm{~g}$ for $10 \mathrm{~min}$. The plasma fraction (supernatant) was separated for evaluation of the total reactive antioxidant potential (TRAP). Mononuclear cells were discarded by aspiration. Erythrocytes were suspended in saline solution $0.9 \% \mathrm{P} / \mathrm{V} \mathrm{NaCl}$ and were washed three times by centrifugation at $300 \mathrm{~g}$ with the same saline solution at $25^{\circ} \mathrm{C}$, and then diluted $1 / 10$ in $1 \mathrm{mM}$ acetic acid and $4 \mathrm{mM}$ 
magnesium sulfate. The protein concentration was determines with the Folin reagent, using bovine serum albumin (grade III) as the standard.

The peripheral markers of oxidative stress assayed were:

\subsubsection{Tert-butyl hydroperoxide initiated chemiluminescence (BOOH-CL)}

The increased values of $\mathrm{BOOH}-\mathrm{CL}$ indicate the occurrence of oxidative stress in the membrane of the erythrocytes due to consume of the endogenous antioxidants. The chemiluminescence associated to lipid peroxidation (BOOH-CL) was measured with a Packard Tricarb model 3355 liquid scintillation counter in the out-of-coincidence mode. This assay estimates indirectly and with high sensitivity the tissue levels of a-tocopherol by inhibition of the propagation step of lipid peroxidation, as discussed by González Flecha et al. (1991). Red blood cells were suspended in $4 \mathrm{~mL}$ of $120 \mathrm{mM} \mathrm{KCl}, 30 \mathrm{mM}$ phosphate buffer, $\mathrm{pH} 7.40$ at $0.1-0.2 \mathrm{mg}$ protein/mL. Low-potassium glass vials of $25 \mathrm{~mm}$ diameter and $50 \mathrm{~mm}$ height filled with the sample suspension were used. Instrument background, in the absence of vials, was $2400 \pm 60$ counts per minutes (cpm) and the emission from the empty vials was $3000 \pm 60 \mathrm{cpm}$. Chemiluminescence measurements were started by the addition of $3 \mathrm{mM}$ tert-butyl hydroperoxide and the counting continued until a maximal level of emission was reached, usually after 20 minutes. Determinations were carried out at $30^{\circ} \mathrm{C}$. The results are expressed as cpm/mg protein (González Flecha et al., 1991).

\subsubsection{Plasma antioxidant capacity (TRAP)}

The decreased values of TRAP in plasma indicate a reduction in the level of plasmatic hydrosoluble antioxidants (i.e., GSH, uric acid, ascorbic acid and bilirubin). The total reactive antioxidant potential of plasma was measured by chemiluminescence. This assay determines total endogenous water soluble antioxidants, mainly glutathione, ascorbic acid, bilirubin and albumin uric acid in plasma. The addition of $10 \mu \mathrm{L}$ of sample to $20 \mathrm{mM} \mathrm{2,2-}$ azobis (2- amidinopropane) (ABAP) in $100 \mathrm{mM}$ phosphate buffer, $\mathrm{pH} 7.40$ and $40 \mu \mathrm{M}$ luminol decreased the chemiluminescence to basal levels and prevented the spike of light emission for a period proportional to the amount of antioxidants present in the sample (induction time, $\delta$ ). The system was calibrated with Trolox (a hydrosoluble vitamin E analogue). The results are expressed as $\mu \mathrm{moL}$ Trolox per $\mathrm{g}$ of organ, or $\mu \mathrm{M}$ Trolox considering $1 \mathrm{~g}$ of tissue as $1 \mathrm{~mL}$ of water (Lissi et al., 1992).

\subsubsection{Thiobarbituric acid reactive substances (TBARS)}

The increase in TBARS results from augmented levels of systemic and neuronal hydroperoxides that lead to an increment in lipid peroxidation. TBARS was assayed by the spectrophotometric determination as described by Fraga et al. (1988). Thiobarbituric acid reacts with malondialdehyde, a product of lipid peroxidation, showing maximal absorbance at $535 \mathrm{~nm}$. The reaction mixture consists of $1 \mathrm{~mL}$ of plasma, $1 \mathrm{~mL}$ of $120 \mathrm{mM} \mathrm{KCl}, 1 \mathrm{~mL}$ of 30 $\mathrm{mM}$ phosphate buffer, $\mathrm{pH} 7.40,0.05 \mathrm{~mL}$ of buthylhydroxytoluene $4 \% \mathrm{w} / \mathrm{v}$ in ethanol, $1 \mathrm{ml}$ of thrichloroacetic acid $20 \% \mathrm{w} / \mathrm{v}$ and $1 \mathrm{~mL}$ thiobarbituric acid $0.7 \% \mathrm{w} / \mathrm{v}$. The deproteinized mixture was heated at $100{ }^{\circ} \mathrm{C}$ for 20 minutes. Results $\left(E=156 \mathrm{mM}^{-1} \mathrm{~cm}^{-1}\right)$ are expressed as nmol/L plasma (Fraga et al., 1988).

\subsection{4 $\mathrm{Cu}-\mathrm{Zn}$ superoxide dismutase (SOD)}

An increase in the activity of the antioxidant enzyme SOD has been regarded as a marker of systemic oxidative stress, since the up-regulation of the antioxidant enzyme expression was 
considered as an adaptive response to the oxidative stress situation. SOD activity was determined by measuring the ability of red blood cells to inhibit the autoxidation of epinephrine at $\mathrm{pH} 10.2$. The increase in absorbance at $480 \mathrm{~nm}$ was $0.025 \mathrm{U}$-min with no added SOD, and $50 \%$ inhibition was achieved by $46 \mathrm{ng} / \mathrm{mL}$ of bovine SOD. One unit of SOD activity was defined as the inhibition of the epinephrine oxidation rate by $50 \%$. The inhibition was determined comparing the regression lines of autoxidation of epinephrine standard solutions against varying amounts of sample. Activity is expressed in U SOD/mg protein (Misra \& Fridovich, 1972; Serra et al., 2000).

\section{Results}

The data given in Table 1 show the association of PD with oxidative stress. BOOH-CL was increased by $86 \%$ and TRAP values showed a decrease of $33 \%$ in PD, together with increases of $19 \%$ in TBARS and 55\% in SOD, by comparison with the healthy controls (Serra et al., 2001; Repetto, 2008).

\begin{tabular}{|c|c|c|c|c|}
\hline Variables & $\begin{array}{c}\text { BOOH-CL } \\
(\mathrm{cpm} / \mathrm{mg} \mathrm{Hb}) \times 10^{2}\end{array}$ & $\begin{array}{c}\text { TRAP } \\
(\mu \mathrm{M} \text { Trolox })\end{array}$ & $\begin{array}{c}\text { TBARS } \\
(\mathrm{nmol} \mathrm{MDA} / \mathrm{mL})\end{array}$ & $\begin{array}{c}\text { SOD } \\
\text { (UsOD/mg } \\
\text { prot.) }\end{array}$ \\
\hline $\begin{array}{l}\text { Parkinson's } \\
\text { Disease }\end{array}$ & $\begin{array}{c}202 \pm 10 \\
p<0.001 \\
n=12\end{array}$ & $\begin{array}{c}242 \pm 25 \\
\mathrm{p}<0.001 \\
\mathrm{n}=12\end{array}$ & $\begin{array}{c}3.46 \pm 0.18 \\
\mathrm{p}<0.05 \\
\mathrm{n}=15\end{array}$ & $\begin{array}{c}15.83 \pm 0.57 \\
\mathrm{p}<0.001 \\
\mathrm{n}=15\end{array}$ \\
\hline
\end{tabular}

Table 1. BOOH-CL and TRAP in erythrocytes and plasma of patients with Parkinson's disease; TBARS in plasma and SOD in erythrocytes. Probabilities as compared against pooled healthy controls $(n=75)$ of comparable ages.

The concentration of non-enzymatic antioxidants decreases during oxidative damage. A lower level of antioxidants as a consequence of a previous situation of oxidative damage will correspond to a higher $\mathrm{BOOH}-\mathrm{CL}$, TBARS and SOD. These three increases are indicative of the occurrence of systemic oxidative stress.

Present results demonstrate that the BOOH-CL, TBARS, TRAP and SOD variables for determining oxidative stress and antioxidant status would be a useful tool for the biochemical and clinical evaluation of patients during the progression of the disease and clinical treatment (Repetto, 2008; Serra et al., 2009).

Chemiluminescence methods allow evaluating and quantifying the toxic oxygen species and antioxidant defenses in blood samples of the patients. They are: tert-butyl hydroperoxide initiated chemiluminescence (BOOH-CL) and total reactive antioxidant potential (TRAP).

Chemiluminescence occurs when a chemical reaction produces an electronically excited species which emits light on its return to the ground state. Singlet oxygen and triplet carbonyl compounds are the most important chemiluminescent species in lipid peroxidation of biological systems (Figure 1).

The experimental conditions defined here for $\mathrm{BOOH}-\mathrm{CL}$ (Figure 1) and TRAP (Figure 2) may be used to evaluate oxidative stress in blood of patients in PD patients. The two assays appear as useful to evaluate the overall level of the non-enzymatic antioxidant defenses in the sample. The substances that constitute the non-enzymatic antioxidant defenses $(\alpha-$ tocopherol, ascorbic acid, retinal, uric acid, albumin, ceruloplasmin, glutathione, etc) 
decrease their concentration during oxidative stress due to their reaction with reactive oxygen or nitrogen species and, in consequence, their elimination.

The levels of methaemoglobin (Met-Hb) are regarded as an index of intracellular damage to the red cell, increased when $\alpha$-tocopherol is consumed and the rate of lipid peroxidation is increased. Scavenging of free radicals by $\alpha$-tocopherol is the first and the most critical step in defending against oxidative damage to the red cells. When $\alpha$-tocopherol is adequate, GSH and ascorbic acid may complement the antioxidant functions of $\alpha$-tocopherol by providing the reducing equivalents necessary for its recycling/regeneration.

On the other hand, when $\alpha$-tocopherol is absent, GSH and ascorbic acid may release transitional metals from the bound forms and/or maintain metal ions in a catalytic state. Free radical generation catalyzed by transition metal ions can in turn initiate oxidative damage to cell membranes. Membrane damage leads to the release of heme compounds of the erythrocytes. The heme compounds released may further promote oxidative damage especially when reducing compounds are present.

The lower level of antioxidants as a consequence of the occurrence of oxidative stress is also sustained by higher values of chemiluminescence (Figures 1 and 2). The increase of $\mathrm{BOOH}-$ $\mathrm{CL}$ is indicative that $\alpha$-tocopherol is the antioxidant consumed in erythrocytes and suggest that reactive oxygen species and lipid peroxidation catalyzed by reduced transition metals may be responsible for the onset of oxidative damage and the occurrence of systemic oxidative stress in patients suffering PD (Table 1).

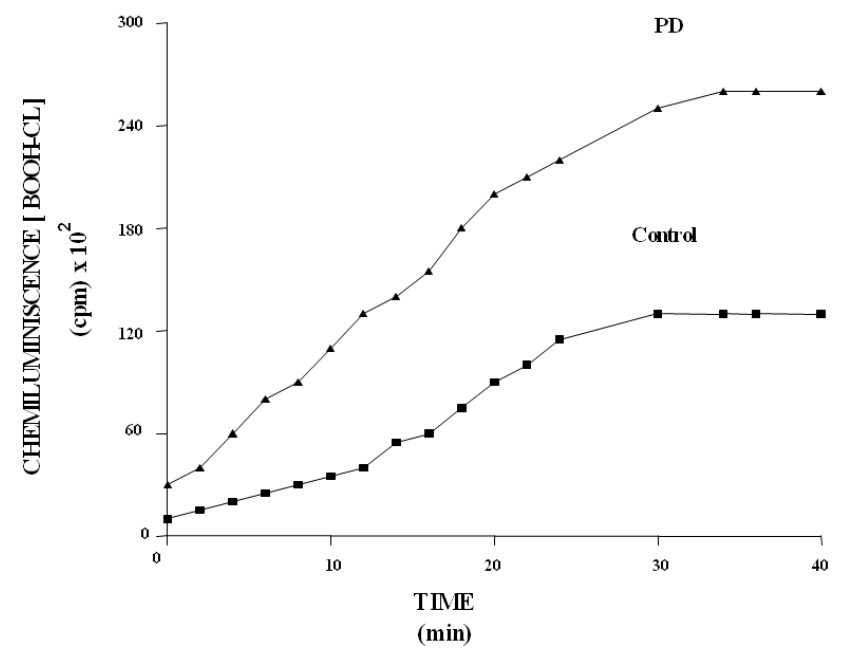

Fig. 1. Photoemission kinetics of chemiluminescence (BOOH-CL) in erythrocytes of a control subject and a PD patient.

The evolution of chemiluminescence shows that at $30 \mathrm{~min}$ of the beginning of the lipid peroxidation propagation step, the erythrocyte's BOOH-CL of PD patients were 3 fold greater than those observed in the control subject (control value: $100 \times 10^{2} \mathrm{cpm}$ ) (Figure 1). These results are in agreement with the consumption time of the endogenous hydrosoluble antioxidants in plasma, showing a $50 \%$ of decrease in the induction time in PD patients compared with control subject (control value: $4 \mathrm{~min}$ ) (Figure 2). 
As cell membranes and lipoproteins contain lipophilic antioxidants and plasma contains hydrophilic antioxidants, that are able to react with lipid peroxyl radicals, eventually terminating the chain reaction the chemiluminescence technique may be applied to study the antioxidant effect of many compounds or the presence of antioxidant molecules in a biological tissue. The reaction between a lipid and hydroperoxyl radicals with a molecule of antioxidant prevent the emission of light (González Flecha et al., 1991; Repetto, 2008).

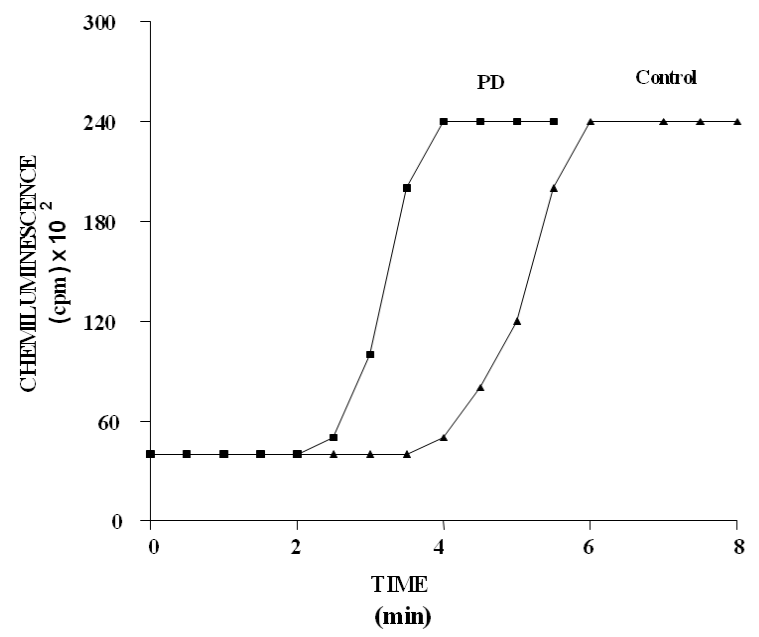

Fig. 2. Time profiles of luminol luminescence with plasma from a PD patient and a control subject.

The biological effects induced by free radicals are neutralized in vivo by antioxidative defense mechanisms, which include ascorbic acid, uric acid, $\alpha$-tocopherol, carotenoids, glutathione and antioxidant enzymes. However, the extensive generation of oxygen reactive species in some pathological conditions appears to overwhelm natural defense mechanisms, thereby reducing dramatically the levels of endogenous antioxidants.

The non-enzymatic antioxidants decrease their concentration during oxidative damage. A lower level of antioxidants as a consequence of a previous situation of oxidative damage will correspond to a higher chemiluminescence. The increase of $\mathrm{BOOH}-\mathrm{CL}$ is indicative of the occurrence of systemic oxidative stress.

Accordingly, there is a statistically significant decrease in the measured TRAP, suggesting that an enhanced susceptibility of erythrocytes to the oxidative stress correlates with a decrease in its antioxidant defenses (Figures 3 and 4).

Chemiluminescence is a simple method to providing tools to evaluate the clinical situation of patients, allowing quantification of the plasma antioxidant content, the correlation with the advance of the pathology, the effects of pharmacological treatments and the relative contribution of total endogenous antioxidants to the plasma.

Chemiluminescence is a collective term, which includes the emission of light by molecules which have been excited to a higher energy level as a result of a chemical reaction. Singlet oxygen or triplet carbonyl compounds are likely to be the most important chemiluminescent species in lipid peroxidation of biological systems; both of them can originate from recombination of two peroxyl radicals to a non-radical product according to Russell's mechanism by a number of chemical pathways. 


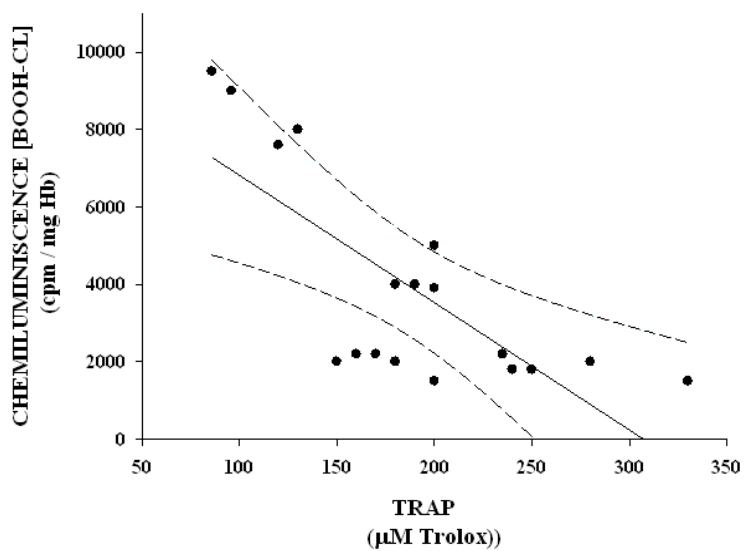

Fig. 3. Correlation between BOOH-CL in erythrocytes and TRAP in plasma of PD patients. Pearson's correlation coefficient was $0.790(\mathrm{p}<0.001)$. The solid line is the linear regression $(r=-0.752)$, dotted lines the $99 \%$ confidence intervals.

Although lipids in the cell are protected from autoxidation by a protein coat and/or by the presence of high concentration of antioxidants, it seems evident that some autoxidation of PUFA in cells must occur. Antioxidant status in biological samples is regarded as an indicator of oxidative stress, and in many cases low antioxidant capacity of tissue and body fluids is a consequence of increased oxidative processes (Halliwell \& Gutteridge, 1984).

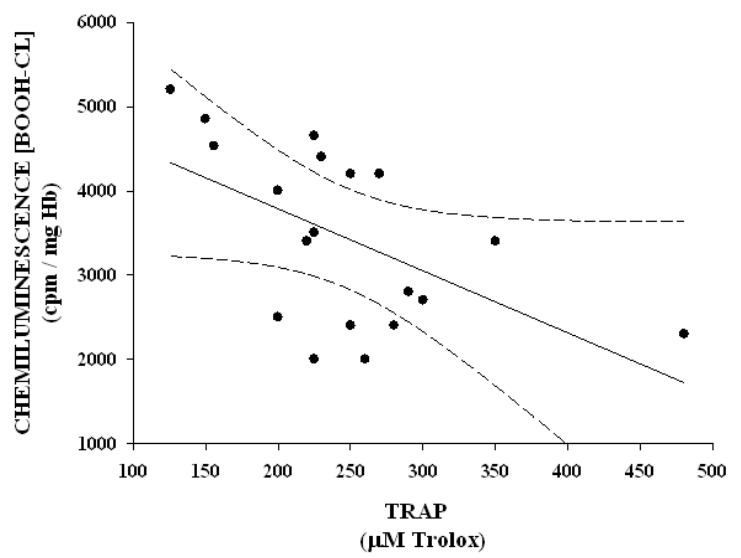

Fig. 4. Correlation between BOOH-CL in erythrocytes and TRAP in plasma of control group. Pearson's correlation coefficient was $0.600(\mathrm{p}<0.01)$. The solid line is the linear regression $(\mathrm{r}$ $=-0.554)$, dotted lines the $99 \%$ confidence intervals.

Close quantitative correspondences were found when TRAP and BOOH-CL were plotted against the Hoehn and Yahr's scale in Parkinson's patients (Figures 5 and 6).

The evidence linking neurodegenerative diseases with oxidative stress suggested that different substances might be involved in Parkinson's, Alzheimer's and Vascular diseases. 


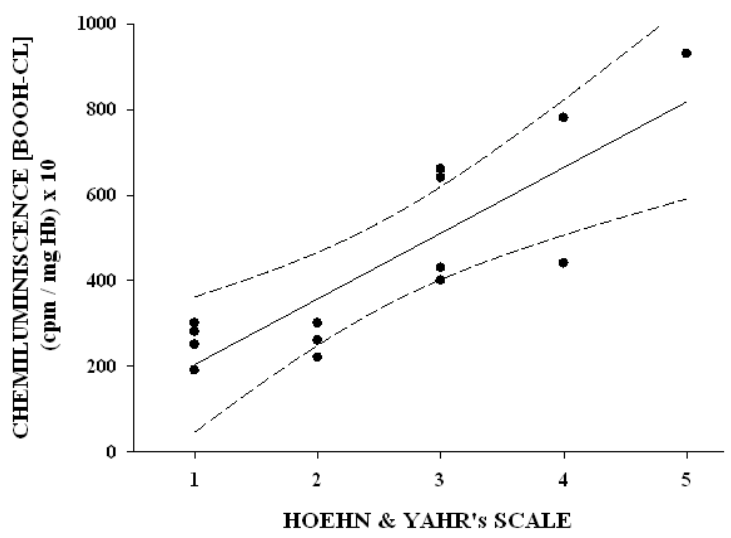

Fig. 5. Correlation between erythrocyte BOOH-CL and Hoehn and Yahr's clinical scale of PD patients (Pearson's correlation coefficient, $r=0.842, p<0.001$ ). The solid line is the linear regression $(r=0.857)$, dotted lines the $99 \%$ confidence intervals.

This hypothesis was tested using Discriminant Analysis in order to find if it is possible to separate PD, Alzheimer's disease patients (AD), Vascular dementia patients (VD) and healthy controls (C) based on the measured biochemical variables (Serra et al., 2001).

The first Discriminant Function (DF) obtained was: DF $1=-18.47$ SOD - 1.21 CAT - 0.99 GSH 3.42 TBARS + 2.42 TRAP - 1.12 Age + 30.23, where CAT and GSH are the values of the antioxidant enzyme catalase and the glutathione system respectively which, albeit not yielding significant differences per se, proved useful when included in the discriminant function.

The values assigned by this function to each observation resulted in the correct identification of $100 \%$ of $\mathrm{PD}, 94 \%$ of $\mathrm{AD}$ and $100 \%$ of $\mathrm{VD}$ as diseased subjects and $93 \%$ of the C group as healthy. It was also possible to discriminate between DAT and VD using the second DF:

DF $2=-1.16 \mathrm{SOD}+0.86 \mathrm{CAT}+1.34 \mathrm{GSH}+2.26 \mathrm{TBARS}-1.35 \mathrm{TRAP}+3.58$ Age -5.59 , which correctly identified $88.9 \%$ of DAT and $73.3 \%$ of VD.

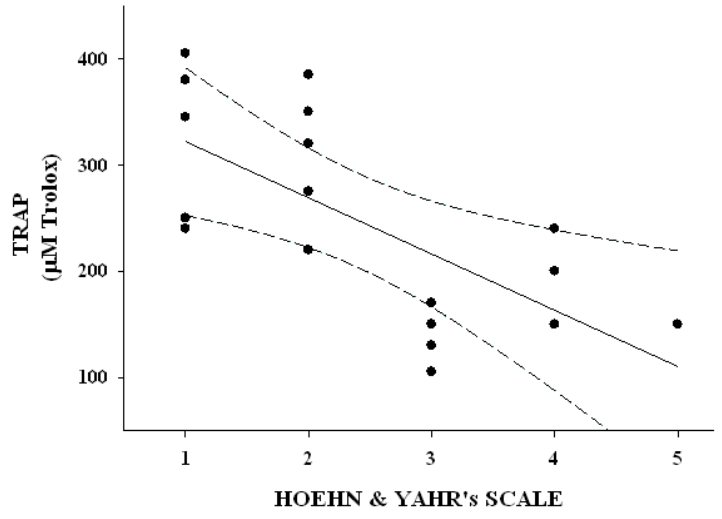

Fig. 6. Correlation between TRAP and Hoehn and Yahr's clinical scale of PD (Pearson's correlation coefficient, $r=0.890, p<0.003)$. Solid line is the linear regression $(r=-0.684)$, dotted lines the $99 \%$ confidence intervals. 
The discriminant functions define four quadrants (Figure 7) with the healthy controls lying in the negative $X$ (first Discriminant Function) region and all the diseased subjects in the positive $X$. The AD patients fall in the positive $X$ and positive $Y$ (second Discriminant Function) and the VD in the positive $\mathrm{X}$ and negative $\mathrm{Y}$. The PD patients were not associated with any of the other groups of patients (9 were classified as AD and 6 as VD).

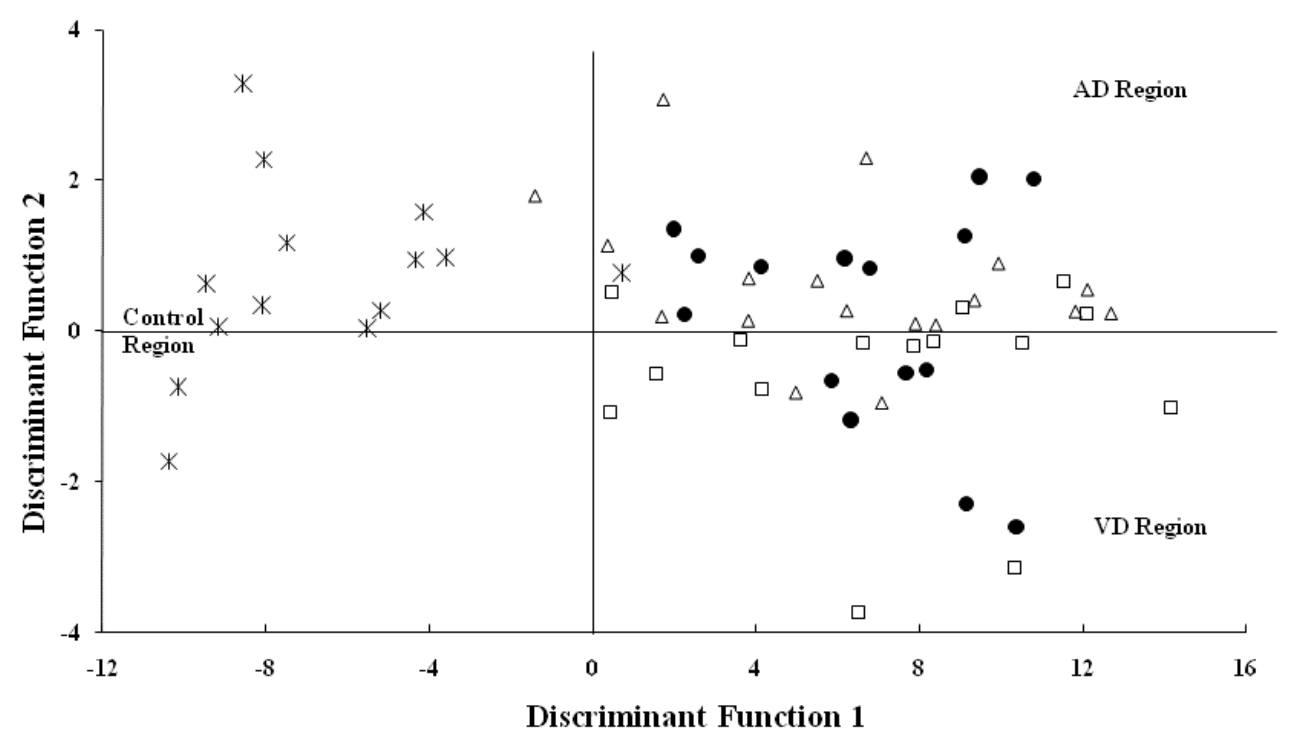

Fig. 7. Plot of pathological and control subjects on the two axes derived from Discriminant Functions. Clinical conditions are: PD patients $(n=15)$ : Filled circles; AD Patients $(n=18)$ : Empty triangles; VD Patients $(n=15)$ : Empty squares; Healthy Controls $(n=14)$ : Asterisks.

The Discriminant Function 2 correctly recognizes $A D$ and VD, showing that these two groups might be considered as separate oxidative disorders (measured by biochemical variables of the peripheral oxidant/antioxidant system). The control and diseased regions are clearly separated, as well as AD and VD regions. PD patients are evenly distributed overlapping AD and VD, suggesting biochemical similarities with both diseases.

The peripheral antioxidant profile of PD shows a degree of overlap (already shown in Figure 7) with those of $\mathrm{AD}$ and VD. While dementias can be readily distinguished from each other, the PD profile might be described as intermediate between AD and VD. This might be explained noting that the main neuronal populations affected are different in each disease. Their identity (dopaminergic, noradrenergic, serotoninergic and cholinergic) is well established: mainly dopaminergic neurons die in PD and cholinergic neurons in $\mathrm{AD}$ patients; while VD doesn't present neuronal selectivity. The three diseases are associated with oxidative disorders predominating in different anatomical areas of the brain. An intermediate mechanism might be hypothesized for the PD patients (Serra et al., 2001).

Table 2 presents the values of the oxidant and antioxidant variables in the three neurological diseases and healthy controls studied obtained in a different protocol (Serra et al., 2009). 


\begin{tabular}{|c|c|c|c|c|c|}
\hline Group & $\begin{array}{c}\text { TBARS } \\
\text { nmol MDA/ml } \\
\text { plasma }\end{array}$ & $\begin{array}{c}\text { TRAP } \\
\mu \mathrm{M} \text { Trolox }\end{array}$ & $\begin{array}{c}\text { SOD } \\
\mathrm{U}_{\mathrm{SOD}} / \mathrm{mg} \\
\text { protein }\end{array}$ & $\begin{array}{c}\text { CAT } \\
\mathrm{k}^{\prime} / \mathrm{ml} \\
\mathrm{RBC}\end{array}$ & $\begin{array}{c}\text { GPx } \\
\mu \mathrm{M} \text { GPx } / \mathrm{ml} \\
\text { RBC }\end{array}$ \\
\hline $\begin{array}{l}\text { Parkinson's } \\
\text { Disease } \\
\mathrm{n}=15\end{array}$ & $\begin{array}{c}3.46 \pm 0.18 \\
p<0.05\end{array}$ & $\begin{array}{l}295 \pm 26 \\
p<0.01\end{array}$ & $\begin{array}{c}15.83 \pm 0.57 \\
p<0.001\end{array}$ & $\begin{array}{c}49.5 \pm 3.4 \\
\text { N.S. }\end{array}$ & $\begin{array}{c}2.1 \pm 0.3 \\
\text { N.S. }\end{array}$ \\
\hline $\begin{array}{l}\text { Alzheimer's } \\
\text { Disease } \\
\mathrm{n}=112\end{array}$ & $\begin{array}{c}3.61 \pm 0.13 \\
p<0.001\end{array}$ & $\begin{array}{c}277 \pm 12 \\
p<0.001\end{array}$ & $\begin{array}{c}17.75 \pm 0.47 \\
p<0.001\end{array}$ & $\begin{array}{l}43.9 \pm 3.0 \\
\text { N.S. }\end{array}$ & $\begin{array}{l}1.8 \pm 0.1 \\
\text { N.S. }\end{array}$ \\
\hline $\begin{array}{l}\text { Vascular } \\
\text { Dementia } \\
\mathrm{n}=57\end{array}$ & $\begin{array}{c}3.50 \pm 0.12 \\
p<0.01\end{array}$ & $\begin{array}{l}309 \pm 18 \\
p<0.001\end{array}$ & $\begin{array}{c}16.69 \pm 0.61 \\
p<0.001\end{array}$ & $\begin{array}{c}39.4 \pm 3.8 \\
\text { N.S. }\end{array}$ & $\begin{array}{l}2.1 \pm 0.2 \\
\text { N.S. }\end{array}$ \\
\hline $\begin{array}{l}\text { Healthy } \\
\text { Controls } \\
n=80\end{array}$ & $2.91 \pm 0.08$ & $410 \pm 19$ & $10.24 \pm 0.28$ & $45.8 \pm 3.9$ & $1.9 \pm 0.2$ \\
\hline
\end{tabular}

Table 2. TBARS, TRAP measured in plasma, the enzymes SOD, CAT and GPx (glutathione peroxidase) measured in erythrocytes of patients with Parkinson's disease, Alzheimer's disease and Vascular dementia. Probabilities as compared against pooled healthy controls of comparable ages. RBC: Red blood cells; N.S.: non-significant differences.

As free radical stress results from an imbalance between free radical production and antioxidant system, it may be possible to measure the antioxidant levels separately or as a total global antioxidant capacity of a biological tissue. The reactive oxygen and nitrogen species are generated in living systems and oxidize a number of cellular constituents like lipids, proteins and DNA. As a consequence of this, antioxidants come into play and act as free radical scavengers, inhibit lipid peroxidation and other free radical mediated processes; they are able to protect the human body from several diseases attributed to the reaction of radicals.

Moreover, the present results show linearity between pairs of oxidative stress variables and the ordering of the neurological patients' diseases along the different regression lines pointing to the existence of an overall balance between oxidative insult, damage and protection (Table 2 and Figures 8 and 9) (Serra et al., 2009).

The linear correlations described between the three variables also include a significant negative linear correlation between plasma TRAP and erythrocyte SOD $(r=-0.980, p<0.001$, not shown), which is implied by the other two relationships.

\section{Conclusions}

PD is a common neurodegenerative movement disorder, which affects increasing numbers of the elderly population. The disorder is characterized by a selective degeneration of dopaminergic neurons in the substantia nigra. Although the molecular mechanism associated with neurodegeneration in PD is not known, it is becoming increasingly evident that neuronal death in this disease is a multifactorial process that may involve monoamino oxidase-mediated abnormal dopamine metabolism, increase of iron levels, hydrogen peroxide generation, transition metal and $\alpha$-synuclein dyshomeostasis, abnormal mitochondrial function and oxidative stress and damage. Free radicals have been postulated as involved 


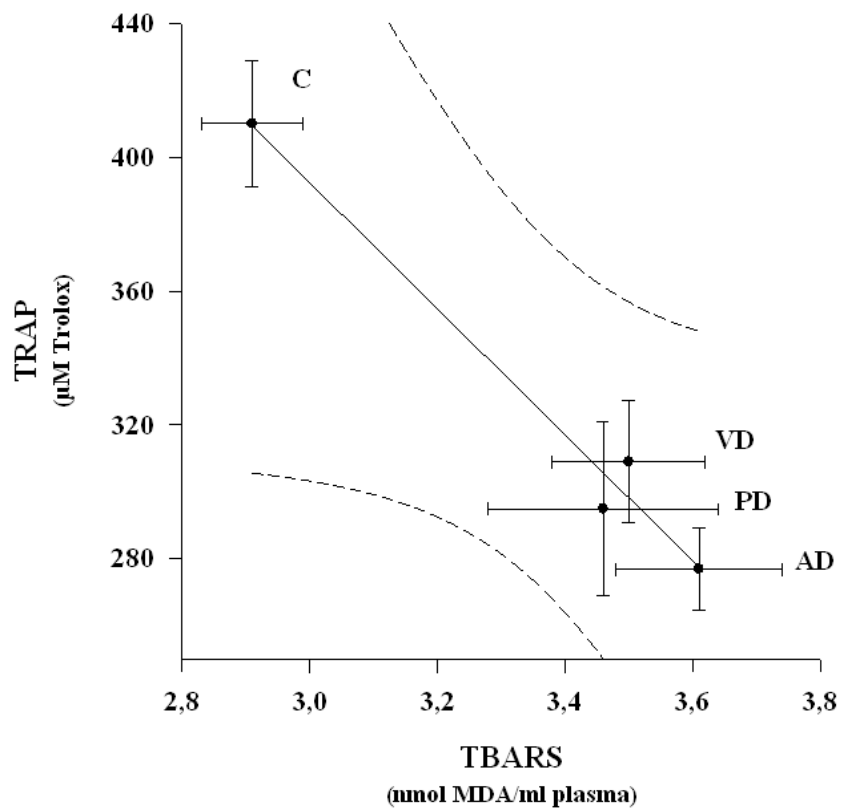

Fig. 8. Correlation between plasma TBARS and plasma TRAP values. Mean values (points) and standard error (bars), solid line is the linear regression $(r=-0.989)$, dotted lines the $99 \%$ confidence intervals. C: healthy controls $(n=80)$; PD: Parkinson's disease patients $(n=15)$; AD: Alzheimer's disease patients $(n=112)$; VD: Vascular Dementia patients $(n=57)$ (Data from Serra et al., 2009).

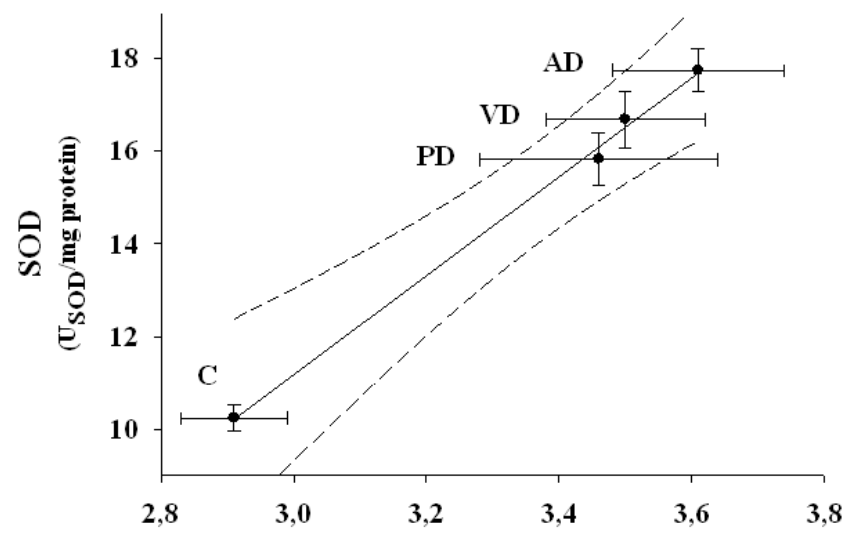

TBARS

(nmol MDA/ml plasma)

Fig. 9. Correlation between plasma TBARS and erythrocyte SOD values $(\mathrm{r}=0.998)$. Statistics and abbreviations as in Figure 8 (Serra et al., 2009). 
in PD disease. The concept of free radical involvement is supported by enhanced basal lipid peroxidation in substantia nigra (Navarro \& Boveris, 2009) and plasma of PD patients, demonstrated by increased levels of TBARS and lipid peroxidation. The assay of oxidative stress parameters in plasma and red blood cells in humans is usually attempted through the determination of: a decreased in the level of antioxidants, and an increase in the by-products of free radical reactions. The increase of BOOH-CL and TBARS are indicative that $\alpha-$ tocopherol is the antioxidant consumed in erythrocytes and suggest that reactive oxygen species and lipid peroxidation catalyzed by reduced transition metals may be responsible for the onset of oxidative damage and the occurrence of systemic oxidative stress in PD. The levels of intracellular (GSH) and plasma antioxidants are reduced in PD patients, suggesting that changes in GSH homeostasis and metabolism are early component of the pathological process of PD. SOD increases point to the existence of oxidative insult and systemic oxidative stress, alongside with the differences indicated by markers representing conditions that change in a few days period, through a marker representing the homeostatic long term response of the bone marrow in the order of 60-80 days.

It is also interesting to note the coincidence resulting from the linear ordering of the responses in relation with the complexity of the pathologies (Figures 8 and 9), accordingly with the simple Sies scale model. The steady-state formation of prooxidants in cells and organs is balanced by a similar rate of their consumption by antioxidants that are enzymatic and/or nonenzymatic. Oxidative stress results from imbalance in this prooxidant/antioxidant equilibrium in favor of the prooxidants (Sies, 1991).

In pathological situations the reactive oxygen species are generated as a consequence of lipid peroxidation and may occur with $\alpha$-tocopherol deficiency. In addition to containing high concentrations of polyunsaturated fatty acids and transitional metals, red blood cells are constantly being subject to various types of oxidative stress. However, red blood cells are protected by a variety of antioxidant systems, capable of preventing most of the adverse effects under normal conditions. Among the antioxidant systems, in the red cells, $\alpha$ tocopherol possesses an important and unique role. $\alpha$-tocopherol may protect the red cells from oxidative damage via a free radical scavenging mechanism or as a structural component of the cell membranes (Repetto, 2008).

Cellular oxidative stress and peroxidation of membrane lipids play a role in the pathogenesis of PD. A condition of systemic oxidative stress, determined in red blood cells by BOOH-CL and SOD activity, and in plasma by TBARS and TRAP, was identified in PD patients. Accordingly, there is a statistically significant decrease in the measured TRAP, suggesting that an enhanced susceptibility of erythrocytes to the oxidative stress correlates with a decrease in its antioxidant defenses. These results indicate that peripheral markers, likely reflecting neuronal conditions in red blood cells and plasma, BOOH-CL, TRAP, TBARS and SOD evaluated by the present procedures, could be a useful complementary measurement when assessing the oxidative stress condition in different clinical pathological situations. Oxidative stress is one of the risk factors, which can initiate and/or promote neurodegeneration in PD, and correlates with the severity of the disease. The concept that free radicals, lipid peroxidation and oxidative stress were involved in the neuronal abnormalities of PD was simultaneous with the recognition of complex I dysfunction in PD. The original idea of oxidative stress has been extended to oxidative and nitrative stress for the protein damage and loss of dopaminergic neurons in Parkinson's disease (Navarro et al., 2009). 


\section{Acknowledgment}

This work was supported by grants from the University of Buenos Aires (B056) and from the PRALIB, CONICET (PIP 6320) from Argentina.

\section{References}

Bender, A.; Krishnan, K.J.; Morris, C.M.; Taylor, G.A.; Reeve, A.K. \& Perry, R.H. (2006). High levels of mitochondrial DNA deletions in substantia nigra neurons in aging and Parkinson's disease. Nature Genetic, Vol. 38, pp. 515-517, ISSN: 1061-4036, EISSN: 1546-1718

Boveris, A. \& Navarro, A. (2008) Brain mitochondrial dysfunction in aging. Life, Vol. 60, No.5, pp. 308-314, ISSN: 1521-6543, EISNN: 1521-6551

Boveris, A.; Repetto, M.G.; Bustamante, J.; Boveris, A.D. \& Valdez, L.B. (2008). The concept of oxidative stress in pathology. In: Álvarez, S.; Evelson, P. (ed.), Free Radical Pathophysiology, pp. 1-17, Transworld Research Network: Kerala, India, ISBN: 97881-7895-311-3

Dalakas, M.C.; Fujii, M.; Li, M. \& McElroy, B. (2000). The clinical spectrum of anti-GAD antibody-positive patients with stiff-person syndrome. Neurology, Vol. 55, pp. 15311535, ISSN: 1080-2371; EISSN: 1538-6899

Domínguez, R.O.; Marschoff, E.R.; Guareschi, E.M.; Repetto, M.G.; Famulari, A.L.; Pagano, M.A. \& Serra, J.A. (2008). Insulin, glucose and glycated haemoglobin in Alzheimer's and vascular dementia with and without superimposed Type II diabetes mellitus condition. Journal of Neural Transmission, Vol. 115, pp. 77-84, ISSN: 0300-9564, EISSN: 1435-1463

Fahn, S.; Elton, R.L. \& UPDRS program members (1987). Unified Parkinson's disease Rating Scale. In: Fahn, S.; Marsden, C.D.; Goldstein, M.; Calne, D.B. (ed.). Recent developments in Parkinson's disease. Macmillan Healthcare Information: Florham Park, NJ, USA; Vol. 2, pp. 153-163

Famulari, A.; Marschoff, E.; Llesuy, S.; Kohan, S.; Serra, J.; Domínguez, R.; Repetto, M.G.; Reides, C. \& Lustig, E.S. de (1996). Antioxidant enzymatic blood profiles associated with risk factors in Alzheimer's and vascular diseases. A predictive assay to differentiate demented subjects and controls. Journal of the Neurological Sciences, Vol. 141, pp. 69-78, ISSN: 0022-510X

Farooqui, T. \& Farooqui, A. (2011) Lipid-mediated oxidative stress and inflammation in the pathogenesis of Parkinson's disease. Parkinson's disease. DOI: 10.4061/2011/247467

Fiszman, M.; D’Eigidio, M.; Ricart, K.; Repetto, M.G.; Llesuy, S.; Borodinsky, L.; Trigo, R.; Riedstra, S.; Costa, P.; Saizar, R.; Villa, A. \& Sica, R. (2003). Evidences of oxidative stress in Familial Amyloidotic Polyneuropathy Type 1. Archives of Neurology, Vol. 60, pp. 593-597, ISSN 0003-9942, EISSN 0375-8540

Fraga, C.; Leibovitz, B. \& Tappel, A. (1988). Lipid peroxidation measured as thiobarbituric acid-reactive substances in tissue slices: characterization and comparison with homogenates and microsomes. Free Radicals in Biology and Medicine, Vol. 4, pp. 155161, ISSN: 0891-5849

Friedlich, A.L.; Smith, M.A.; Zhu, X.; Takeda, A.; Nunomura, A.; Moreira, P. \& Perry, G. (2009). Oxidative stress in Parkinson's disease. The Open Patholology Journal, Vol. 3 , pp. 38-42, ISSN: 1874-3757 
Gatto, E.; Carreras, M.C.; Pargament, G.; Reides, C.; Repetto, M.G.; Llesuy, S.; Fernández Pardal, M. \& Poderoso, J. (1996). Neutrophil function nitric oxide and blood oxidative stress in Parkinson's disease. Movement Disorders, Vol. 11, pp. 261-267, ISSN: 0885-3185

Gatto, E.; Carreras, C.; Pargament, G.; Riobó, N.; Reides, C.; Repetto, M.; Fernández Pardal, N.; Llesuy, S. \& Poderoso, J. (1997). Neutrophyl function nitric oxide and blood oxidative stress in Parkinson's Disease. Focus Parkinson's Disease, Vol. 9, pp. 12-14

Gibb, W.R. \& Lees, A.J. (1988). The relevance of the Lewy body to the pathogenesis of idiopathic Parkinson's disease. Journal Neurology Neurosurgery Psychiatry, Vol. 51, pp. 745-752, ISSN: 00223050. EISSN: 1468330X

González Flecha, B.; Llesuy, S. \& Boveris, A. (1991). Hydroperoxide-initiated chemiluminescence: assay for oxidative stress in biopsies of heart, liver and muscle. Free Radicals in Biology and Medicine, Vol. 10, pp. 93-100, ISSN: 0891-5849

Halliwell, B. \& Gutteridge, J.M.C. (1984). Oxygen toxicity, oxygen radicals, transition metals and disease. Biochemical Journal, Vol. 218, pp. 1-14, ISSN: 0264-6021

Hoehn, M.M. \& Yahr, M.D. (1967). Parkinsonism: onset, progression and mortality. Neurology, Vol. 17, pp. 427-442, ISSN: 1080-2371; EISSN: 1538-6899

Hughes, A.J.; Ben-Shlomo, S.E.; Daniel, S.E. \& Lees, A.J. (1992). What features improve the accuracy of clinical diagnosis in Parkinson's disease: a clinicopathological study? Neurology, Vol. 2, pp. 1142-1146, ISSN: 1080-2371; EISSN: 1538-6899

Kozlowski, H.; Janck-Klos, A.; Brasun, J.; Gaggelli, E.; Valensin D. \& Valensin, G. (2009). Copper, iron, and Zinc ions homeostasis and their role in neurodegenerative disorders (metal uptake, transport, distribution and regulation). Coordination Chemistry Review, Vol. 253, pp. 2665-2685, ISSN: 0010- 8545

Lissi, E.; Pascual, C. \& Del Castillo, M. (1992). Luminol luminescence induced by 2, 2'-Azobis (2-amidinopropane) thermolysis. Free Radical Research Communications, Vol. 17, pp. 299- 311, 1992, ISSN: 8755-0199

Lustig, E.S. de; Serra, J.A.; Kohan, S.; Canziani, G.A.; Famulari, A.L. \& Domínguez, R.O. (1993). Copper zinc superoxide dismutase activity in red blood cells and serum in demented patients and in aging. Journal of the Neurological Sciences, Vol. 115, pp. 1825, ISSN: 0022-510X

McNamara, P.; Durso, R. \& Harris, E. (2007). "Machiavellianism" and frontal dysfunction: evidence from Parkinson's disease. Cognitive neuropsychiatry, Vol. 12, pp. 285-300, ISSN: 0264-3294, EISSN: 1464-0627

Misra, H. \& Fridovich, I. (1972). The role of superoxide anion in the autooxidation of epinephrine and a simple assay for superoxide dismutase. The Journal of Biological Chemistry, Vol. 247, pp. 3170-3175, ISSN: ISSN 0021-9258, EISSN 1083-351X

Movement Disorder Society Task Force on Rating Scales for Parkinson's disease: The Unified Parkinson's Disease Rating Scale (UPDRS): status and recommendations (2003). Movement Disorders, Vol. 18, pp. 738-50, ISSN: 0885-3185

Navarro, A. \& Boveris, A. (2004). Rat brain and liver mitochondria develop oxidative stress and lose enzymatic activities on aging. American Journal of Physiology - Regulatory, Integrative and Comparative Physiology, Vol. 287, pp. 1244-1249, ISSN: 0363-6119, EISSN: 1522-1490

Navarro, A.; Boveris, A.; Bández, M.J.; Sánchez-Pino, M.J.; Gómez, C.; Muntane, G. \& Ferrer, I. (2009). Human brain cortex: mitochondrial oxidative damage and 
adaptive response in Parkinson's disease and in dementia with Lewy bodies. Free Radicals in Biology and Medicine, Vol. 46, pp. 1574-1580, ISSN: 0891-5849

Navarro, A. \& Boveris, A. (2009). Brain mitochondrial dysfunction and oxidative damage in Parkinson's disease. Journal of Bioenergetics and Biomembranes, Vol. 41, pp. 517-521. ISSN: 0145-479X. EISSN: 1573-6881

Navarro, A.; Bández, M.; Gómez, C.; Sánchez-Pino, M.; Repetto, M.G. \& Boveris, A. (2010). Effects of rotenone and pyridaben on complex I electron transfer and on mitochondrial nitric oxide synthase functional activity. Journal of Bioenergetics and Biomembranes, Vol. 42, pp. 405-412, ISSN: 0145-479X. EISSN: 1573-6881

Opazo, C.; Barría, M.I.; Ruiz, F.H. \& Inestrosa, N.C. (2003). Copper reduction by copper binding proteins and its relation to neurodegenerative diseases. Biometals, Vol. 16, pp. 91-98, ISSN: 0966-0844, EISSN: 1572-8773

Pardo Andreu, G.L; Inada, N.M.; Vercesi, A.E. \& Curti, C. (2009). Uncoupling and oxidative stress in liver mitochondrial isolated from rats with acute iron overload. Archives Toxicology, Vol. 83, pp. 47-53, ISSN: 0340-5761, EISSN: 1432-0738

Petrozzi, L.; Ricci, G.; Giglioli, N.J.; Siciliano, G. \& Mancuso, M. (2007). Mitochondria and neurodegeneration. Bioscience Reports, Vol. 27, pp. 87-104, ISSN: 0144-8463, EISSN: 1573-4935

Quinn N. (1989). Multiple system atrophy-the nature of the beast. Journal Neurology Neurosurgery Psychiatry, Vol. 52, pp. 78-89, ISSN: 00223050. EISSN: 1468330X

Repetto, M.G.; Reides, C.; Evelson, P.; Kohan, S.; Lustig, E.S. de \& Llesuy, S. (1999). Peripheral markers of oxidative stress in probable Alzheimer patients. European Journal of Clinical Investigation, Vol. 29, pp. 643-649, ISSN: 0014-2972, EISSN: 13652362

Repetto, M.G. \& Llesuy, S.F. (2004). Peripheral markers of oxidative stress in neurological patients. Reprinted from XIII Bienal Meeting of the Society for Free Radical Research International (SFRR). In: Boveris, A. (ed.), Proceedings of the Society for Experimental Biology and Medicine, John Wiley \& Sons Inc Publisher: NJ, USA, pp. 251-255, ISSN: 0037-9727, EISSN: 1525-1373

Repetto, M.G. (2008). Clinical use of chemiluminescence assays for the determination of systemic oxidative stress. In: Álvarez, S.; Evelson P. (ed.), Handbook of chemiluminescent methods in oxidative stress assessment. Transworld Research Network: Kerala, India; pp. 163-194, ISBN: 978-81-7895-334-2

Repetto, M.G. \& Boveris A. (2011). Transition metals: bioinorganic and redox reactions in biological systems. In: Transition metals: uses and characteristics. Nova Science Publishers Inc (ed.): New York, USA. In press, ISBN: 978-1-61761-110-0

Rossi, L.; Lombardo, M.; Ciriolo, M. \& Rotilio, G. (2004). Mitochondrial dysfunction in neurodegenerative diseases associated with copper imbalance. Neurochemical Research, Vol. 29, pp. 493-504, ISSN: 0364-3190, EISSN: 1573-6903

Schrag, A.; Ben-Shlomo, Y. \& Quinn, N. (2002). How valid is the clinical diagnosis of Parkinson's disease in the community? Journal Neurology Neurosurgery Psychiatry, Vol. 73, pp. 529-534, ISSN: 00223050. EISSN: 1468330X

Serra, J.A.; Marschoff, E.R.; Domínguez, R.O.; Lustig, E.S. de; Famulari, A.L.; Bartolomé, E.L. \& Guareschi, E.M. (2000). Comparison of the determination of superoxide dismutase and antioxidant capacity in neurological patients using two different procedures. Clinica Chimica Acta, Vol. 301, pp. 87-102, ISSN: 0009-8981 
Serra, J.A.; Domínguez, R.O.; Lustig, E.S. de; Guareschi, E.M.; Famulari, A.L.; Bartolomé, E.L. \& Marschoff, E.R. (2001). Parkinson's disease is associated with oxidative stress: comparison of peripheral antioxidant profiles in living Parkinson's, Alzheimer's and vascular dementia patients. Journal of Neural Transmission, Vol. 108, pp. 1135-1148, ISSN/ISBN: 03009564

Serra, J.A.; Domínguez, R.O.; Marschoff, E.R.; Guareschi E.M.; Famulari, A.L. \& Boveris, A. (2009) Systemic oxidative stress associated with the neurological diseases of aging. Neurochemical Research, Vol. 34, pp. 2122-2132, ISSN/ISBN: 03643190

Sies, H. (1991). Role of reactive oxygen species in biological processes. Wiener Klinische Wochenschrift, Vol. 69, pp. 965-968, ISSN: 1613-7671

Sigleton, A.B.; Farrer, M.; Johnson, J.; Singleton, A.; Hague, S.; Kachergus, J.; Hulihan, M.; Peuralinna, T.; Dutra, A.; Nussbaum, R.; Lincoln, S.; Crawley, A.; Hanson, M.; Maraganore, D.; Adler, C.; Cookson, M.R.; Muenter, M.; Baptista, M.; Miller, D.; Blancato, J.; Hardy, J. \& Gwinn-Hardy, K. (2003). Alpha-synuclein locus triplication causes Parkinson's disease. Science, Vol. 302, pp. 841, ISSN: 0036-8075, EISSN 10959203

Spencer, W.; Jeyabalan, J.; Kichambre, S. \& Gupta, R. (2011). Oxidatively generated DNA damage after $\mathrm{Cu}$ (II) catalysis of dopamine and related catecholamine neurotransmitters and neurotoxins: Role of reactive oxygen species. Free Radicals in Biology and Medicine, Vol. 50, pp. 139-147, ISSN: 0891-5849 


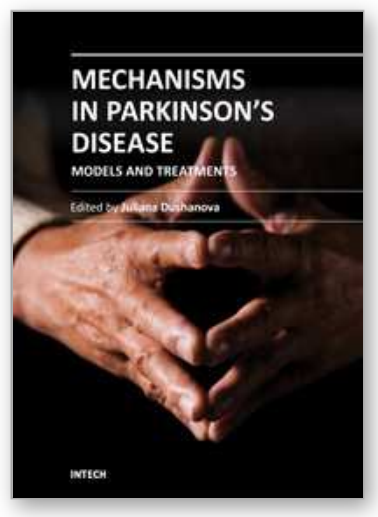

\author{
Mechanisms in Parkinson's Disease - Models and Treatments \\ Edited by Dr. Juliana Dushanova
}

ISBN 978-953-307-876-2

Hard cover, 582 pages

Publisher InTech

Published online 08, February, 2012

Published in print edition February, 2012

Parkinson's disease (PD) results primarily from the death of dopaminergic neurons in the substantia nigra. Current PD medications treat symptoms; none halt or retard dopaminergic neuron degeneration. The main obstacle to developing neuroprotective therapies is a limited understanding of the key molecular mechanisms that provoke neurodegeneration. The discovery of PD genes has led to the hypothesis that misfolding of proteins and dysfunction of the ubiquitin-proteasome pathway are pivotal to PD pathogenesis. Previously implicated culprits in PD neurodegeneration, mitochondrial dysfunction, and oxidative stress may also act in part by causing the accumulation of misfolded proteins, in addition to producing other deleterious events in dopaminergic neurons. Neurotoxin-based models have been important in elucidating the molecular cascade of cell death in dopaminergic neurons. PD models based on the manipulation of PD genes should prove valuable in elucidating important aspects of the disease, such as selective vulnerability of substantia nigra dopaminergic neurons to the degenerative process.

\title{
How to reference
}

In order to correctly reference this scholarly work, feel free to copy and paste the following:

Marisa G. Repetto, Raúl O. Domínguez, Enrique R. Marschoff and Jorge A. Serra (2012). Free Radicals, Oxidative Stress and Oxidative Damage in Parkinson's Disease, Mechanisms in Parkinson's Disease - Models and Treatments, Dr. Juliana Dushanova (Ed.), ISBN: 978-953-307-876-2, InTech, Available from: http://www.intechopen.com/books/mechanisms-in-parkinson-s-disease-models-and-treatments/free-radicalsoxidative-stress-and-oxidative-damage-in-parkinson-s-disease

\section{INTECH}

open science | open minds

\section{InTech Europe}

University Campus STeP Ri

Slavka Krautzeka 83/A

51000 Rijeka, Croatia

Phone: +385 (51) 770447

Fax: +385 (51) 686166

www.intechopen.com

\section{InTech China}

Unit 405, Office Block, Hotel Equatorial Shanghai

No.65, Yan An Road (West), Shanghai, 200040, China 中国上海市延安西路65号上海国际贵都大饭店办公楼 405 单元

Phone: +86-21-62489820

Fax: $+86-21-62489821$ 
(C) 2012 The Author(s). Licensee IntechOpen. This is an open access article distributed under the terms of the Creative Commons Attribution 3.0 License, which permits unrestricted use, distribution, and reproduction in any medium, provided the original work is properly cited. 